\section{Commentary: Minimally invasive esophagectomy (MIE) and robotic-assisted esophagectomy (RAMIE): We need high-volume surgeons, more science, and more robots!}

James D. Luketich, MD, Arjun Pennathur, MD, and Inderpal Sarkaria, MD, MBA

The accompanying article by Groth and Burt ${ }^{1}$ provides an articulate and timely summary of progress in minimally invasive esophagectomy (MIE). Important references are cited, and it is noted that advances in technology and surgical experiences in other areas made MIE possible.

Their acknowledgement of the early work by Luketich and colleagues in Pittsburgh to establish MIE as safe and feasible is noted, but of equal importance was the education that took place in Pittsburgh and subsequently around the world to help other surgeons develop MIE skills. ${ }^{2-4}$ More than 100 Continuing Medical Education courses took place over this period, with hundreds of visiting surgeons from around the world gaining observational and handson training in MIE at The University of Pittsburgh Medical Center. These visiting surgeons frequently presented their own early work, greatly contributing to the Pittsburgh efforts to develop and master MIE. In addition, over this period, more than 100 residents and 80 advanced fellows trained in MIE and went on to develop their own centers of excellence.

\footnotetext{
From the Department of Cardiothoracic Surgery, University of Pittsburgh School of Medicine, and the University of Pittsburgh Medical Center, Pittsburgh, Pa.

Disclosures: James D. Luketich owns stock in Intuitive Surgical and Express Scripts. Inderpal Sarkaria is a speaker and consultant for Intuitive Surgical. Arjun Pennathur reported no conflicts of interest.

The Journal policy requires editors and reviewers to disclose conflicts of interest and to decline handling or reviewing manuscripts for which they may have a conflict of interest. The editors and reviewers of this article have no conflicts of interest.

Received for publication May 5, 2021; revisions received May 5, 2021; accepted for publication May 5, 2021; available ahead of print May 11, 2021.

Address for reprints: James D. Luketich, MD, Department of Cardiothoracic Surgery, University of Pittsburgh School of Medicine, C800 PUH, 200 Lothrop St, Pittsburgh, PA 15213 (E-mail: luketichjd@upmc.edu).

J Thorac Cardiovasc Surg 2021;162:705-6

$0022-5223 / \$ 36.00$

Copyright (c) 2021 by The American Association for Thoracic Surgery

https://doi.org/10.1016/j.jtcvs.2021.05.011
}
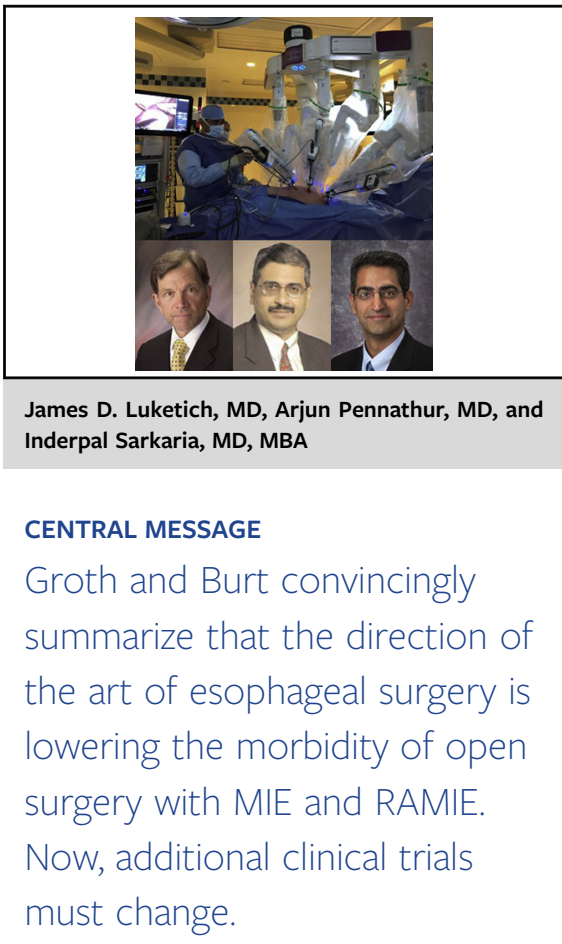

Although no historical summary can include every important contribution, one of the pivotal efforts in MIE progress outlines some of the problems we faced in turning surgical art into science and deserves inclusion. Our early trial efforts began in 1999 with a small group of surgeons from Pittsburgh who hoped to convince the world that MIE was the future. With the assistance of other surgeons, we developed a multicenter, prospective, controlled MIE trial that was presented to the Eastern Cooperative Oncology Group (ECOG) in 2001. The concept was approved in 2002 (ECOG 2202), and with help from David Sugarbaker and others, the National Cancer Institute intergroup approved funding in 2003. Ultimately, ECOG 2202 made it through 17 institutional review boards and opened to accrual in 2004. Due to ECOG 2202's study design, the study was paused in 2005 for the first-stage analysis and reopened in 2006, and accrual completed in 2008. The preliminary results were presented at American Society of Clinical Oncology in $2009,,^{5}$ and with further 3-year oncologic follow-up period, the final results were ultimately published in 2015. ${ }^{6}$ Thus, from trial concept to publication, over 15 years elapsed. As academic surgeons, we must work toward a more efficient way of developing prospective trials if we are to transform the direction of the art of surgery into science. 
Additional strengths of their paper include a summary of various levels of evidence that support MIE, and now RAMIE, as viable alternatives to open esophagectomy. ${ }^{7-9}$ Importantly, they point out that further work is needed to address some of the technical issues faced and the need for cost analyses in future trials. These randomized trials and 10 favorable meta-analyses showed that the surgical community across the globe contributed to a change toward a less-morbid operation for esophageal cancer. ${ }^{10}$

They also point out that important components of esophagectomy lack scientific evidence to guide the ideal approach, whether performing open esophagectomy or MIE. The debate over transhiatal, Ivor Lewis, or Mckeown in the open era was never resolved, leaving significant unanswered surgical questions. ${ }^{11}$ This continued into the MIE era, leading to a host of minimally invasive approaches and hybrids and slow progress of MIE. ${ }^{12}$ In the RAMIE era, similar problems exist, and opinion rather than evidence is guiding details of the procedure. ${ }^{13}$ Various steps, which are technically challenging and time-consuming, are being omitted by some perhaps to simply "get it done." We need clinical trials to determine which steps are important and to avoid decisions that shorten the time of RAMIE or MIE by questionable acts of omission. Important questions that remain to be studied include the ideal location and type of anastomosis, best conduit diameter, pyloroplasty or not, the need for feeding jejunostomy and nutritional management, extent of nodal dissection, and nonsurgical questions, including the ideal neoadjuvant regimen. We agree with these important points and in Pittsburgh, we are finalizing accrual to our randomized MIE/ RAMIE trial on pyloroplasty (NCT03740542).

The paper by Groth and Burt summarizes the evidence that MIE and RAMIE are less-morbid operations than open esophagectomy and importantly point out there is more work to do. If robotic technology enables more surgeons to master MIE, RAMIE may emerge as the procedure of choice. We agree with the authors closing points that prospective trials like ROBOT-2 (Robot-assisted
Minimally Invasive Thoraco-laparoscopic Esophagectomy Versus Minimally Invasive Esophagectomy for Resectable Esophageal Cancer, a Randomized Controlled Trial) should help us advance the art and the science of esophageal surgery and that future trials promise to provide evidenced-based knowledge to all facets of esophageal cancer treatment.

\section{References}

1. Groth SS, Burt BM. Minimally invasive esophagectomy: direction of the art J Thorac Cardiovasc Surg. 2021;162:701-4.

2. Luketich JD, Schauer PR, Christie NA, Weigel TL, Raja S, Fernando HC, et al. Minimally invasive esophagectomy. Ann Thorac Surg. 2000;70:906-12.

3. Luketich JD, Alvelo-Rivera M, Buenaventura PO, Christie NA, McCaughan JS, Litle VR, et al. Minimally invasive esophagectomy: outcomes in 222 patients. Ann Surg. 2003;238:486-95.

4. Luketich JD, Pennathur A, Awais O, Levy RM, Keeley S, Shende M, et al. Outcomes after minimally invasive esophagectomy: review of over 1000 patients. Ann Surg. 2012;256:95-103.

5. Luketich JD, Pennathur A, Catalano PJ, Swanson SJ, de Hoyos AL, Maddaus MA, et al. Results of a phase II multicenter study of minimally invasive esophagectomy (Eastern Cooperative Oncology Group Study E2202). American Society of Clinical Oncology. J Clin Oncol. 2009;27(15 suppl):4516.

6. Luketich JD, Pennathur A. Franchetti Y, Catalano PJ, Swanson S, Sugarbaker DJ, et al. Minimally invasive esophagectomy: results of a prospective phase II multicenter trial-the Eastern Cooperative Oncology Group (E2202) study. Ann Surg. $2015 ; 261: 702-7$.

7. Sarkaria IS, Rizk NP, Goldman DA, Sima C, Tan KS, Bains MS, et al. Early quality of life outcomes after robotic-assisted minimally invasive and open esophagectomy. Ann Thorac Surg. 2019;108:920-8.

8. Vimolratana M, Sarkaria IS, Goldman DA, Rizk NP, Tan KS, Bains MS, et al. Two-year quality of life outcomes after robotic-assisted minimally invasive and open esophagectomy. Ann Thorac Surg. November 4, 2020 [Epub ahead of print].

9. Brady JJ, Witek TD, Luketich JD, Sarkaria IS. Patient reported outcomes (PROs) after minimally invasive and open esophagectomy. J Thorac Dis. 2020;12: 6920-4.

10. Shah RD, Levy RM, Luketich JD. Minimally invasive Ivor Lewis esophagectomy. In: Luketich JD, ed. Master Techniques in Surgery: Esophageal Surgery. Philadelphia: Wolters Kluwer Health; 2014:273-88.

11. Hulscher JBF, van Sandick J, de Boer AG, Wijnhoven BP, Tijssen JG, Fockens P, et al. Extended transthoracic resection compared with limited transhiatal resection for adenocarcinoma of the esophagus. N Engl J Med. 2002;347:1662-9.

12. Law S, Wong J. Use of minimally invasive oesophagectomy for cancer of the oesophagus. Lancet Oncol. 2002;3:215-22.

13. Witek TD, Melvin TJ, Luketich JD, Sarkaria IS. Open, minimally invasive, and robotic approaches for esophagectomy: what is the approach algorithm? Thorac Surg Clin. 2020;30:269-77. 